Matematikai Közlemények

VII. kötet, 2019

doi:10.20312/dim.2019.01

\title{
On Papkovich-Neuber type representations for solutions of the Navier-Lamé equation in spatial star-shaped domains
}

\author{
Sándor Zsuppán \\ Berzsenyi Dániel Evangélikus (Líceum) Gimnázium és Kollégium \\ zsuppans@gmail.com
}

\begin{abstract}
ÖSSZEFOGLALÓ. Papkovich-Neuber típusú reprezentációs képletet vezetünk le a lineáris rugalmasságtan Navier-Lamé egyenletének megoldásaira térbeli csillagszerü tartományban. A kapott eredményt összehasonlítjuk a már létező hasonló eredményekkel.
\end{abstract}

ABSTRACT. We develop a Papkovich-Neuber type representation formula for the solutions of the Navier-Lamé equation of linear elastostatics for spatial star-shaped domains. This representation is compared to the existing ones.

\section{Introduction}

Papkovich-Neuber type formulae represent the solutions of the Navier-Lamé equation of linear elastostatics via auxiliary harmonic potentials. This technique is also suitable for generating solutions of the Stokes equations for the creeping flow of an uncompressible fluid. It originates in the papers of Papkovich [6] and Neuber [4]. An important variant of this representation was given by Kratz [2] for the Stokes equation, where the uniqueness of the harmonic potentials in the representation was also proved. The Kratz representation [2] is valid for general planar domains, but in the spatial case only for star-shaped ones. Another variant of it can be found in [3] also for spatial star-shaped domains. In [8] the present author proved that the representation formulae in [2] and [3] are equivalent, moreover, generalized them for the Navier-Lamé equation of linear elastostatics. The representation formulae derived in [2] and [8] solve the problem of eliminating the scalar harmonic potential from the general PapkovichNeuber representation in the special case of spatial star-shaped domains maintaining simultaneously the completeness of the representation, see [5] and also the references given there. Altough these formulae are ment to derive analytic solutions of the respective equations, they can also be utilized in numerical methods, see for example [1].

In this paper we derive another representation similar to that in [8], Theorem 5.3 for a modified Stokes type equation also equivalent to the Navier-Lamé system. The connection of this representation to existing ones is also investigated.

\section{Main result}

In this paper we develop representation formulae for the solutions $u \in C^{2}(\Omega)$ and $q \in$ $C^{1}(\Omega)$ of the equation 


$$
-\Delta u=\operatorname{rot} q \text { and } \operatorname{rot} u=\tilde{v} q,
$$

where $\Omega$ is a spatial star-shaped domain with respect to the origin. (1) is similar to the system

$$
-\Delta u=\operatorname{grad} p \text { and }-\operatorname{div} u=v p,
$$

which was (although not in this form) considered in [8]. Note that both (1) and (2) are equivalent to the Navier-Lamé equation

$$
(\lambda+\mu) \operatorname{grad} \operatorname{div} u+\mu \Delta u=0
$$

in linear elastostatics, where $\lambda$ and $\mu$ are the Lamé constants. These constants satisfy usually $\mu>0$ and $\lambda+\frac{2}{3} \mu>0$, where the latter quantity is the compression modulus. In order to establish the connection of (3) to (1) and (2) we have to set $q=\frac{\lambda+\mu}{\lambda+2 \mu} \operatorname{rot} u$ and $p=\frac{\lambda+\mu}{\mu} \operatorname{div} u$, respectively. We also have $v=-\frac{\mu}{\lambda+\mu}$ in (2) and $\tilde{v}=\frac{\lambda+2 \mu}{\lambda+\mu}=1-v$ in (1).

Theorem 1. Let $\Omega \subset \mathbb{R}^{n}$ be a star-shaped domain with respect to the origin, and set $\tilde{v} \in \mathbb{R}$, $\tilde{v}>0, \tilde{v} \neq \frac{1}{4}, 1$. The functions $u \in C^{2}(\Omega)$ and $q \in C^{1}(\Omega)$ satisfy (1) if and only if there exists a harmonic function $\tilde{h} \in C^{2}(\Omega)$ such that

$$
\begin{gathered}
u(x)=\frac{1}{2} \nabla(x \cdot \tilde{h}(x))+\frac{1}{2} \operatorname{rot}(x \times \tilde{h}(x))+(1-2 \tilde{v}) \tilde{h}(x), \\
q(x)=-2 \operatorname{rot} \tilde{h}(x)-4 \nabla \phi(x)
\end{gathered}
$$

for $x \in \Omega$. The harmonic function $\tilde{h}$ is unique and we have

$$
\tilde{h}(x)=\frac{2}{1-4 \widetilde{v}}\left(u(x)+\frac{1}{4} x \times q(x)-\frac{1}{4(1-\widetilde{v})} x \operatorname{div} u(x)+x \times \nabla \phi(x)\right),
$$

where the function $\phi$ is harmonic in $\Omega$ and defined by

$$
\phi(x)=-\frac{1}{4} \int_{0}^{1} t^{4 \widetilde{v}} x \cdot q(t x) d t .
$$

ProOF. We need the following identities, where we assume the existence and continuity of the involved scalar and vector valued functions. These are the same identities used in [2] and [8].

$$
\begin{gathered}
x \operatorname{div} u+x \times \operatorname{rot} u=u+\nabla(x \cdot u)+\operatorname{rot}(x \times u), \\
-\Delta u=-\nabla \operatorname{div} u+\operatorname{rot} \operatorname{rot} u, \\
\operatorname{div}(x \times u)=-x \cdot \operatorname{rot} u, \\
\operatorname{div}(\phi x)=3 \phi+x \cdot \nabla \phi, \\
\operatorname{rot}(\phi x)=-x \times \nabla \phi, \\
\operatorname{rot}(x \times \nabla \phi)=-\nabla(\phi+x \cdot \nabla \phi)+x \Delta \phi, \\
\nabla\left(r^{2} \phi\right)=2 \phi x+r^{2} \nabla \phi, \text { for } r=|x|, \\
\Delta(x \cdot u)=x \cdot \Delta u+2 \operatorname{div} u,
\end{gathered}
$$




$$
\begin{gathered}
\Delta(x \times u)=x \times \Delta u+2 \operatorname{rot} u, \\
\Delta(\phi x)=x \Delta \phi+2 \nabla \phi, \\
\Delta(x \times \nabla \phi)=x \times \nabla \Delta \phi .
\end{gathered}
$$

From the expression (7) of $\phi$ we obtain setting $k(x)=x \cdot q(x)$ with integration by parts that

$$
\begin{aligned}
x \cdot \nabla \phi(x) & =-\frac{1}{4} \int_{0}^{1} t^{4 \widetilde{v}} x \cdot(\nabla k)(t x) d t=-\frac{1}{4} \int_{0}^{1} t^{4 \widetilde{v}} \frac{d}{d t}(k(t x)) d t \\
& =-\frac{1}{4}\left[t^{4 \widetilde{v}} k(t x)\right]_{0}^{1}+\frac{1}{4} \int_{0}^{1} 4 \tilde{v} t^{4 \widetilde{v}-1} k(t x) d t=-\frac{1}{4} x \cdot q(x)-4 \tilde{v} \phi(x) .
\end{aligned}
$$

Hence, the function $\phi$ defined by (7) satisfies the equation

$$
4 \tilde{v} \phi(x)+x \cdot \nabla \phi(x)+\frac{1}{4} x \cdot q(x)=0 .
$$

Taking the divergence of the second equation of (1) gives $\operatorname{div} q=0$ in a view of $\tilde{v}>0$. Moreover, by (1) and (9) we have $\Delta q=-\operatorname{rot} \operatorname{rot} q=\operatorname{rot} \Delta u=\Delta \operatorname{rot} u=\tilde{v} \Delta q$, which means $\Delta q=0$ using $\tilde{v} \neq 1$. This implies by (15) that $\Delta k=x \cdot \Delta q+2 \operatorname{div} q=0$ and

$$
\Delta \phi(x)=-\frac{1}{4} \int_{0}^{1} t^{4 \widetilde{v}+2}(\Delta k)(t x) d t=0 .
$$

That is, the function $\phi$ is harmonic. Note also, that $\tilde{v}>0$ is sufficient for the integral in (7) to be well defined.

First assume, that $u$ and $q$ are given by (4) and (5) with harmonic $\tilde{h}$ and $\phi$. Using the identities (9), (15) and (16) along with (19) there follows

$$
\begin{aligned}
-\Delta u & =-\frac{1}{2} \nabla(x \cdot \Delta \tilde{h}+2 \operatorname{div} \tilde{h})-\frac{1}{2} \operatorname{rot}(x \times \Delta \tilde{h}+2 \operatorname{rot} \tilde{h})-(1-2 \tilde{v}) \Delta \tilde{h} \\
& =-\nabla \operatorname{div} \tilde{h}-\operatorname{rot} \operatorname{rot} \tilde{h}=-2 \operatorname{rot} \operatorname{rot} \tilde{h}=\operatorname{rot} q, \\
\operatorname{rot} u & =\frac{1}{2}(\nabla \operatorname{div}(x \times \tilde{h})-\Delta(x \times \tilde{h}))+(1-2 \tilde{v}) \operatorname{rot} \tilde{h} \\
& =-2 \tilde{v} \operatorname{rot} \tilde{h}+\frac{1}{4} \nabla(x \cdot(-2 \operatorname{rot} \tilde{h}))=\tilde{v}(q+4 \nabla \phi)+\frac{1}{4} \nabla(x \cdot(q+4 \nabla \phi)) \\
& =\tilde{v} q+\nabla\left(4 \tilde{v} \phi(x)+x \cdot \nabla \phi(x)+\frac{1}{4} x \cdot q(x)\right)=\tilde{v} q .
\end{aligned}
$$

Hence $u$ and $q$ satisfy (1).

In the opposite direction, we assume that $u$ and $q$ satisfy (1). For the calculation we use repeatedly

$$
\nabla \operatorname{div} u=\Delta u+\operatorname{rot} \operatorname{rot} u=-\operatorname{rot} q+\operatorname{rot} \tilde{v} q=-(1-\tilde{v}) \operatorname{rot} q
$$

as a consequence of (1). By $\Delta \phi=0$ and (16) we have $\Delta(x \times \nabla \phi)=0$ and

$$
\begin{aligned}
\Delta \tilde{h} & =\frac{2}{1-4 \tilde{v}}\left(\Delta u+\frac{1}{4} \Delta(x \times q)-\frac{1}{4(1-\tilde{v})} \Delta(x \operatorname{div} u)+\Delta(x \times \nabla \phi)\right) \\
& =\frac{2}{1-4 \tilde{v}}\left(-\operatorname{rot} q+\frac{1}{4}(x \times \Delta q+2 \operatorname{rot} q)-\frac{1}{4(1-\tilde{v})}(x \Delta \operatorname{div} u+2 \nabla \operatorname{div} u)\right) \\
& =\frac{2}{1-4 \tilde{v}}\left(-\operatorname{rot} q+\frac{1}{2} \operatorname{rot} q-\frac{1}{4(1-\tilde{v})}(x \operatorname{div} \operatorname{rot} q-2(1-\tilde{v}) \operatorname{rot} q)\right)=0,
\end{aligned}
$$


that is, the function $\tilde{h}$ defined by (6) is harmonic. We calculate by (8), (12), (13) and (19) that

$$
\begin{aligned}
\operatorname{rot} \tilde{h}= & \frac{2}{1-4 \tilde{v}}\left(\tilde{v} q+\frac{1}{4}(x \operatorname{div} q+x \times \operatorname{rot} q-q-\nabla(x \cdot q))+\frac{1}{4(1-\tilde{v})} x \times \nabla \operatorname{div} u\right. \\
& +(-\nabla(\phi+x \cdot \nabla \phi)+x \Delta \phi)) \\
= & \frac{2}{1-4 \tilde{v}}\left(\tilde{v} q+\frac{1}{4} x \times \operatorname{rot} q-\frac{1}{4} q-\frac{1}{4} \nabla(x \cdot q)-\frac{1}{4(1-\tilde{v})} x \times(1-\tilde{v}) \operatorname{rot} q\right. \\
& -\nabla(\phi+x \cdot \nabla \phi))=\frac{2}{1-4 \tilde{v}}\left(\frac{4 \tilde{v}-1}{4} q-\nabla\left(\phi+x \cdot \nabla \phi+\frac{1}{4} x \cdot q\right)\right) \\
= & -\frac{1}{2} q-2 \nabla \phi .
\end{aligned}
$$

From this we obtain (5) by rearrangeing. We also calculate by (10) and (11) that

$$
\begin{aligned}
\operatorname{div} \tilde{h} & =\frac{2}{1-4 \tilde{v}}\left(\operatorname{div} u-\frac{1}{4} x \cdot \operatorname{rot} q-\frac{1}{4(1-\tilde{v})}(3 \operatorname{div} u+x \cdot \nabla \operatorname{div} u)\right) \\
& =\frac{2}{1-4 \tilde{v}}\left(\frac{1-4 \tilde{v}}{4(1-\tilde{v})} \operatorname{div} u-\frac{1}{4} x \cdot \operatorname{rot} q-\frac{1}{4(1-\tilde{v})} x \cdot \nabla(-(1-\tilde{v}) \operatorname{rot} q)\right) \\
& =\frac{1}{2(1-\tilde{v})} \operatorname{div} u .
\end{aligned}
$$

We compose the expressions for $\operatorname{rot} \tilde{h}$ and $\operatorname{div} \tilde{h}$ as

$$
\frac{1}{2}(x \operatorname{div} \tilde{h}+x \times \operatorname{rot} \tilde{h})=\frac{1}{4(1-\tilde{v})} x \operatorname{div} u-\frac{1}{4} x \times q-x \times \nabla \phi .
$$

On the other hand we have by (6) that

$$
\left(\frac{1}{2}-2 \tilde{v}\right) \tilde{h}=u+\frac{1}{4} x \times q-\frac{1}{4(1-\tilde{v})} x \operatorname{div} u+x \times \nabla \phi .
$$

Adding the latter two expressions and using (8) there follows

$$
\frac{1}{2} \nabla(x \cdot \tilde{h})+\frac{1}{2} \operatorname{rot}(x \times \tilde{h})+(1-2 \tilde{v}) \tilde{h}=\frac{1}{2}(x \operatorname{div} \tilde{h}+x \times \operatorname{rot} \tilde{h})+\left(\frac{1}{2}-2 \tilde{v}\right) \tilde{h}=u,
$$

that is, we have obtained (4) as intended.

Finally we prove the uniqueness of the harmonic function $\tilde{h}$ in the representation (4). Assume that the expression (4) for $u$ is valid for two harmonic functions $\tilde{h}_{1}$ and $\tilde{h}_{2}$. Subtracting these two expressions and setting $\tilde{h}=\tilde{h}_{1}-\tilde{h}_{2}$ gives

$$
\frac{1}{2} \nabla(x \cdot \tilde{h})+\frac{1}{2} \operatorname{rot}(x \times \tilde{h})+(1-2 \tilde{v}) \tilde{h}=0
$$

for the harmonic function $\tilde{h}$. Taking first the divergence and then the rotation of (20) gives

and

$$
0=\frac{1}{2} \Delta(x \cdot \tilde{h})+(1-2 \tilde{v}) \operatorname{div} \tilde{h}=2(1-\tilde{v}) \operatorname{div} \tilde{h}
$$

$$
\begin{array}{r}
0=\frac{1}{2} \operatorname{rot} \operatorname{rot}(x \times \tilde{h})+(1-2 \tilde{v}) \operatorname{rot} \tilde{h}=\frac{1}{2} \nabla \operatorname{div}(x \times \tilde{h})-\frac{1}{2} \Delta(x \times \tilde{h})+(1-2 \tilde{v}) \operatorname{rot} \tilde{h} \\
=-\frac{1}{2} \nabla(x \cdot \operatorname{rot} \tilde{h})-\operatorname{rot} \tilde{h}+(1-2 \tilde{v}) \operatorname{rot} \tilde{h}=-\frac{1}{2}(4 \tilde{v} \operatorname{rot} \tilde{h}+\nabla(x \cdot \operatorname{rot} \tilde{h})) .
\end{array}
$$

The first equation implies $\operatorname{div} \tilde{h}=0$ by $\tilde{v} \neq 1$, while from the second equation we obtain

$$
4 \tilde{v} x \cdot \operatorname{rot} \tilde{h}+x \cdot \nabla(x \cdot \operatorname{rot} \tilde{h})=0 \text {. }
$$


This equation is very similar to (19). Its solution is $x \cdot \operatorname{rot} \tilde{h}=0$, which we substitute into the second of the latter equations. There follows

$$
\tilde{v} \operatorname{rot} \tilde{h}=0 \text {, }
$$

which implies $\operatorname{rot} \tilde{h}=0$ by $\tilde{v}>0$. Comparing (8) and (20) gives

$$
-\frac{1}{2}(-\tilde{h}+x \operatorname{div} \tilde{h}+x \times \operatorname{rot} \tilde{h})+(1-2 \tilde{v}) \tilde{h}=\left(\frac{1}{2}-2 \tilde{v}\right) \tilde{h}
$$

which on the other hand implies $\tilde{h}=0$ by $\tilde{v} \neq \frac{1}{4}$. Hence we have uniqueness for the harmonic function $\tilde{h}$ in the representation formula (4).

Remark 1. The Lamé constants usually satisfy $\mu>0$ and $\lambda+\frac{2}{3} \mu>0$, which mean $\frac{\lambda}{\mu}>-\frac{2}{3}$. This implies $1<\tilde{v}<4$ for the parameter $\tilde{v}=\frac{\lambda+2 \mu}{\lambda+\mu}$ in Theorem 1 . Hence, the assumptions for the parameter $\tilde{v}$ in Theorem 1 are satisfied for every pair of Lamé constants.

Remark 2. An analogous representation for the solutions of (2) in [8] is

$$
\begin{gathered}
u(x)=-\frac{1}{2} \nabla(x \cdot h(x))-\frac{1}{2} \operatorname{rot}(x \times h(x))+(1-2 v) h(x), \\
p(x)=2 \operatorname{div} h(x),
\end{gathered}
$$

where the unique harmonic function $h$ is defined by

$$
h(x)=\frac{2}{3-4 v}\left(u(x)+\frac{1}{4} p(x) x-\frac{1}{4(1-v)} x \times \operatorname{rot} u(x)+x \times \nabla \psi(x)\right)
$$

with $\psi(x)=-\frac{1}{4(1-v)} \int_{0}^{1} t^{4(1-v)} x \cdot \operatorname{rot} u(t x) d t$. If we compare this definition of $\psi$ to (7) and we also take into account $\tilde{v}=1-v$ and the second equation in (1), then we can conclude that in fact $\psi=\phi$. Moreover, comparing this with (1), (2), (6) and (23) gives

$$
h(x)=-\tilde{h}(x)+\frac{1}{1-4 \widetilde{v}} x \times q(x) .
$$

Hence the representation for solutions of (1) is in fact the same as the representation in [8], Theorem 5.3 for solutions of (2).

Remark 3. Theorem 1 of this paper (along with the related Theorem 5.3 in [8]) solves the problem of eliminating the scalar harmonic potential from the general Papkovich-Neuber representation for the solution of the Navier-Lamé equations in spatial star-shaped domains. Decesive in this regard is the solvability of equation (19) for star-shaped domains by the harmonic function (7). For the elimination of the scalar Papkovich-Neuber potential a very similar equation is considered in [5], Section 3, see equation (3.1) in [5]. 
Remark 4. If we impose a homogeneuous Dirichlet boundary condition on the function $u$ in (1) and (2), then we can interpret these as eigenvalue problems for the Schur complement operators

$$
\mathcal{S}_{\mathrm{div}}=-\operatorname{div}\left(-\Delta^{-1}\right) \nabla \text { and } \mathcal{S}_{\mathrm{rot}}=\operatorname{rot}\left(-\Delta^{-1}\right) \operatorname{rot}
$$

connected to the Stokes problem on a spatial star-shaped domain. They were studied for example in [7], see also the references given there.

\section{References}

[1] Hou L.S. and Manouzi H., A div-curl formulation of the Stokes boundary value problem based on a harmonic representation formula, Appl. Math. Lett. Vol. 6, No. 6 (1993), 23-27. doi.org/10.1016/0893-9659(93)90072-U

[2] Kratz W., On the representation of Stokes flows, SIAM J. Math. Anal. 22(2), (1991), 414-423. doi.org/10.1137/0522027

[3] Kratz W. and Lindae A., A representation formula for three-dimensional Stokes flows, Zeitschrift für Analysis und ihre Anwendungen 11(1992)3, 371-375. doi.org/10.4171/ZAA/600

[4] Neuber H., Ein neuer Ansatz zur Lösung räumlicher Probleme der Elastizitätstheorie, Journal of Applied Mathematics and Mechanics 14(4), (1934), 203-212. doi.org/10.1002/zamm.19340140404

[5] Millar R.F., On the completeness of the Papkovich potentials, Quarterly of Applied Mathematics 41(4) (January 1984), 385-393. https://www.jstor.org/stable/43637214

[6] Papkovich P.F.,Solution Générale des équations differentielles fondamentales d'élasticité exprimée par trois fonctions harmoniques, Compt. Rend. Acad. Sci. Paris 195(1932), 513-515.

https://fr.wikisource.org/w/index.php?title=Fichier\%3AComptes_rendus_hebdomadaires_des_s\%C3\%A9an ces_de_1\%E2\%80\%99Acad\%C3\%A9mie_des_sciences\%2C_tome_195\%2C_1932.djvu\&page=513

[7] Velte $\mathbf{W}$., On inequalities of Friedrichs and Babuška-Aziz in dimension three, Journal of Analysis and its Applications 17(4), (1998), 843-857. doi.org/10.4171/ZAA/854

[8] Zsuppán S., On representations of Stokes flows and of the solutions of Navier's equation for linear elasticity, Analysis 28(2), (2008), 219-237. doi.org/10.1524/anly.2008.0910 